\title{
FALTA DE COERÊNCIA NA RESPOSTA AO CORONAVÍRUS ENTRE O MERCOSUL, SEUS ESTADOS-MEMBROS E A OMS
}

\author{
LACK OF COHERENCE IN THE COVID-19 RESPONSE AMONGST \\ MERCOSUR, ITS MEMBER STATES, AND THE WHO
}

DOI: $10.5380 / \operatorname{cg} . v 10 i 3.81887$

Cristhofer Weiland²

Mayra Coan Lago3

\begin{abstract}
Resumo
Em fevereiro de 2020, o Brasil registrou um caso de COVID-19, configurando o primeiro oficial da América do Sul e entre os Estados-membros do Mercado Comum do Sul. No mês seguinte, o vírus já havia se espalhado por todas as regiões do mundo, sendo o surto da COVID-19 caracterizado pela Organização Mundial da Saúde (OMS) como uma pandemia. A Organização conclamou a comunidade internacional para cooperar no combate ao vírus e, nos meses seguintes, realizou uma série de ações e recomendações para mobilizar os diversos atores do cenário internacional. Nosso objetivo é compreender se as recomendações da OMS têm sido seguidas pelo Mercosul e pelos Estados-membros domesticamente. Para lográ-lo, realizamos um mapeamento das principais recomendações da OMS e um levantamento das ações e manifestações do Mercosul referentes ao combate da pandemia, desde março de 2020 até junho de 2021. Também apresentamos algumas das principais ações tomadas no combate à pandemia do coronavírus pelos Estados-membros do Mercosul a fim de observar se eles seguiram as que foram propostas pela Organização. A partir da reflexão observamos que, embora o bloco tenha seguido as recomendações gerais da OMS por meio de encontros e declarações conjuntas em prol do combate regional, domesticamente, os Estados-membros do bloco adotaram medidas que contrastam com algumas recomendações da OMS e com os encontros e declarações do Mercosul.
\end{abstract}

Palavras-Chave: Mercosul; Organização Mundial da Saúde; Estados-membros; Covid-19; pandemia.

\begin{abstract}
In February 2020, Brazil registered a case of Covid-19, making it the first official one in South America and among the member states of the Southern Common Market. In the following month, the virus had already spread to all regions of the world, with the Covid-19 outbreak characterized by the World Health Organization (WHO) as a pandemic. The organization called on the entire international community to cooperate in combating the virus and, in the following months, carried out a series of actions and recommendations in order to mobilize the various actors in the international scenery. We aim to understand whether the WHO

\footnotetext{
${ }^{1}$ Este artigo está licenciado sob a Licença Creative Commons Attribution (CC BY 4.0), sendo permitido o compartilhamento com reconhecimento da autoria e publicação inicial nesta revista.

${ }^{2}$ Mestre em História, Relações Internacionais e Cooperação pela Universidade do Porto (UPORTO), Portugal. Professor de Relações Internacionais da Escola Superior de Relações Internacionais (ESRI). E-mail: crisweiland@gmail.com. ORCID: https://orcid.org/o000-0003-2629-5786.

3 Doutora em História Social pela Universidade de São Paulo (USP). Professora de Relações Internacionais do Centro Universitário Fundação Santo André (CUFSA), Santo André-SP. E-mail: mcoann@ @hotmail.com. ORCID: https://orcid.org/0000-0001-7018-4683.
} 
recommendations have been followed by Mercosur and by its member States domestically. To achieve this, we mapped the main WHO recommendations and a survey of Mercosur actions and manifestations related to the fight against the pandemic, from March 2020 to June 2021. We also present some of the main actions taken in the fight against the coronavirus pandemic by the Mercosur Member States, to check if they followed the WHO recommendations. Based on this reflection, we observed that, although the bloc has sought to follow the WHO general recommendations through joint meetings and declarations in favor of regional combat, domestically the member states of the bloc have adopted measures that contrast with the WHO recommendations, as well as the Mercosur meetings and declarations.

Keywords: Mercosur; World Health Organization; Member States; Covid-19; pandemic.

\section{INTRODUÇÃO}

No final de dezembro de 2019, a Organização Mundial da Saúde (OMS) foi alertada pelas autoridades chinesas sobre vários casos de pneumonia em Wuhan. No início de janeiro de 2020, elas informaram que identificaram um novo tipo de coronavírus no país, que se espalhava rapidamente. Menos de um mês depois da notificação, em 30 de janeiro de 2020, a OMS declarou que o surto do novo coronavírus constituía uma Emergência de Saúde Pública de Importância Internacional (ESPII), o mais alto nível de alerta da Organização, a fim de aprimorar a coordenação, cooperação e solidariedade global para interromper a propagação do vírus (OMS, 2021).

Apesar desta medida, o vírus se espalhou rapidamente por todas as regiões e países do mundo. Na América do Sul, no dia 26 de fevereiro de 2020, o Brasil registrou um caso de Covid-19, configurando o primeiro oficial da região e entre os países-membros do Mercado Comum do Sul (Mercosul)4. Nas duas primeiras semanas de março, Argentina, Paraguai e Uruguai tiveram seus primeiros casos registrados, nos dias 3, 7 e 13, respectivamente, seguidos por outros países da região. Neste contexto de propagação do vírus a OMS caracterizou a Covid-19 como uma pandemia no dia 11 de março de 2020, conclamando a comunidade internacional a cooperar para o combate ao vírus.

A pandemia impactou, de formas diferentes, muitas regiões e países do mundo nos âmbitos humanitários, sanitários, políticos, econômicos e sociais. Especificamente no caso da América Latina e do Caribe, segundo o informe especial Covid-19 $n^{o} 1$ da Comissão Econômica para a América Latina e Caribe (CEPAL), intitulado "América Latina y el Caribe ante la pandemia del COVID-19 Efectos económicos y sociales”, publicado em 3 de abril de 2020, no tocante aos efeitos econômicos, a pandemia impacta pela diminuição da atividade econômica de seus principais sócios comerciais, pela queda dos preços dos produtos primários e deterioração das trocas econômicas, pela

\footnotetext{
4 Em 1991, mediante o Tratado de Assunção, assinado pelos presidentes do Brasil, Argentina, Paraguai e Uruguai, foi criado o Mercado Comum do Sul (Mercosul) a fim de alcançar a livre circulação de bens, serviços e fatores produtivos entre seus membros, através da eliminação de direitos alfandegários, restrições nãotarifárias à circulação de mercado e de qualquer outra medida de efeito equivalente. Nos anos 2000, o Mercosul foi ampliado, incorporando a Venezuela, que está suspensa do bloco desde 2017. Além dos membros permanentes, o bloco tem como membros associados Bolívia, Chile, Colômbia, Equador, Peru, Guiana e Suriname.
} 
interrupção das cadeias globais de valor, pela menor demanda dos serviços de turismo e pela intensificação da aversão ao risco e deterioração das condições financeiras mundiais (CEPAL, 2020).

No tocante aos efeitos sociais, o complicado cenário também foi deteriorado afetando as áreas da saúde, educação e emprego. Assim, houve um aumento da desigualdade social, da pobreza e pobreza extrema, da fome e do desemprego (CEPAL, 2020). Em meados de julho de 2021, momento em que escrevemos este artigo, a América Latina é considerada o epicentro da pandemia, concentrando o maior número de mortos e contaminados por Covid-19 por milhão de habitantes (OUR WORLD IN DATA, 2021; WHO, 2021a)5.

Os distintos impactos inseridos nos contextos nacionais geraram ações domésticas variadas dos governantes. Deste modo, mesmo em uma situação de crise sanitária de caráter global, muitos governos implementaram políticas nacionais desconsiderando as recomendações da OMS acerca da solidariedade global/regional, algo que também podemos notar entre os países da América do Sul e mais especificamente entre os países-membros do Mercosul.

Em um contexto anterior à pandemia, os resultados econômicos e sociais já não apresentavam bons números; contudo, em 2019, os países do Mercosul estiveram alinhados e fecharam o maior acordo de livre comércio entre blocos com a União Europeia. Com a pandemia, é possível notar um esforço conjunto dos países-membros do bloco em combater a Covid-19 através de uma série de reuniões com autoridades e promulgações de declarações de colaboração regional. Contudo, há uma tensão nas relações bilaterais entre países do bloco e desencontro de algumas das recomendações da OMS e do Mercosul6.

Neste cenário pandêmico, composto por momentos de cooperação e de tensão, a OMS tem proposto uma série de recomendações em âmbito mundial e regional. Nosso objetivo é compreender se as recomendações da OMS têm sido seguidas pelo Mercosul, como bloco, e pelos países-membros domesticamente. Para lograr o objetivo, este artigo tem duas partes principais, além desta introdução e das considerações finais. Na primeira parte, realizamos um mapeamento das principais recomendações da OMS a respeito da pandemia de Covid-19 e um levantamento das ações e manifestações do Mercosul referentes ao combate da pandemia, desde março de 2020 até junho de 2021. Na segunda parte, apresentamos algumas das principais ações tomadas no combate à pandemia de Covid-19 pelos países-membros a fim de observar se eles seguiram as que foram propostas pela Organização e os impactos destas medidas.

\footnotetext{
5 Embora os dados sejam registrados como "América do Sul" e "Américas" pelo Our World in Data e OMS, respectivamente, ambos revelam números muito superiores de mortos e contaminados quando comparados com outras regiões.

${ }^{6}$ Em maio de 2020, durante uma entrevista em uma rádio, o presidente argentino Alberto Fernández declarou que o "Brasil era um risco muito grande para a região" devido ao descontrole e aumento exponencial de infectados no país (GLOBO, 2020). No mesmo mês, o presidente paraguaio Mario Abdo Benítez também afirmou que o Brasil era uma "grande ameaça" para o combate à pandemia e para o seu país. A percepção do Brasil como uma "ameaça" e as ações decorrentes desta percepção, como o fechamento das fronteiras, pode ser notado em outros países do Mercosul ou membros associados, como Argentina, Uruguai, Paraguai e Bolívia (BBC, 2020a).
} 


\section{AS AÇÕES DA OMS E DO MERCOSUL PARA O COMBATE À PANDEMIA DA COVID-19}

A pandemia da Covid-19 surge em um cenário complexo em que o mundo está cada vez mais globalizado, integrado e interconectado. No entanto, o combate a um problema comum global, que demanda uma resposta conjunta e coordenada de todos os atores do Sistema Internacional, tem evidenciado os desafios da cooperação internacional.

Nas Relações Internacionais, a cooperação internacional é um elemento fundamental que figura desde as abordagens teóricas clássicas, como o realismo e o idealismo, formuladas a partir do pós-Primeira Guerra Mundial, até as mais contemporâneas da disciplina, ainda que com percepções distintas acerca da possibilidade de os Estados e outros atores do Sistema Internacional cooperarem e em que circunstâncias. A cooperação internacional também é uma dimensão marcante das relações internacionais, que tem se expandido desde a Segunda Guerra Mundial até os dias atuais como prática institucionalizada pelos governos. Esta expansão, combinada com a percepção de que cada vez mais os Estados estavam interdependentes e de que os fenômenos transnacionais estavam mudando o caráter do Sistema Internacional, possibilitou que uma série de autores refletissem sobre o fenômeno e a possibilidade da cooperação internacional a partir da década de 1970, como os cientistas políticos norte-americanos Robert Keohane e Joseph Nye (1989).

A cooperação internacional está presente em todas as áreas, conta com muitas dimensões e diversos atores. De acordo com Eiiti Sato (2010), ela indica que duas ou mais nações não resolvem questões ou agem de forma individualizada e isolada. Deste modo, frente a uma questão compartilhada, governos e outros atores do Sistema Internacional desenvolvem padrões comuns e formulam programas que considerem os problemas e os benefícios que podem ser estendidos para mais de uma sociedade ou mesmo para toda a comunidade internacional.

O autor também adverte que a cooperação deve ser pensada como o oposto ao unilateralismo e não ao conflito, pois a existência da cooperação deve considerar a possibilidade de existirem pontos conflitantes, reais ou potenciais, mas que ainda assim as partes envolvidas estão dispostas a buscar soluções negociadas e, na medida do possível, satisfatórias para as partes.

As breves considerações que tecemos a respeito da cooperação internacional auxiliam na compreensão dos eventos recentes relacionados à pandemia da Covid-19. A conjuntura demanda uma maior cooperação internacional que pode ser observada em algumas ações de solidariedade, como no compartilhamento de conhecimento técnico e científico, colaborações profissionais, materiais e logísticas e avanços das pesquisas em relação ao combate, tratamento, criação, distribuição e doação de vacinas entre os países e outros atores internacionais. Contudo, em contraste com as ações de solidariedade, é possível notar a busca dos Estados por soluções que priorizem suas próprias sobrevivências, como na corrida pelos insumos (equipamentos, respiradores, máscaras e vacinas) e na apropriação de produtos médicos que seriam exportados para outros países (FONSECA, 2021). 
As tentativas de cooperação internacional e respectivos desafios também podem ser observados dentro das organizações internacionais, como a Organização Mundial da Saúde (OMS), criada em 1948, membro do sistema da Organização das Nações Unidas, composta por 194 países7. O alerta da ocorrência de uma pneumonia atípica na China que a OMS recebeu no dia 31 de dezembro de 2019 está inserido no contexto do Regulamento Sanitário Internacional (RSI ou IHR). No dia 7 de janeiro de 2020, a organização confirmou que era um novo vírus, denominado Sars-CoV-2, sendo a etiologia da nova doença denominada "Doença por Coronavírus de 2019" (Covid-19). O diretorgeral da OMS, seguindo o estabelecido pelo RSI, convocou uma reunião do Comitê de Emergência que, no fim de janeiro, recomendou a declaração do surto de Covid-19 como uma "Emergência de Saúde Pública de Importância Internacional (ESPII)” (BUSS, ALCÁZAR e GALVÃO, 2020).

No início do mês seguinte, a organização lançou o Plano Estratégico de Preparação e Resposta (SPRP) da OMS. Ainda em fevereiro, a organização anunciou as Diretrizes de Planejamento Operacional para os Planos de Ação Nacional e realizou um fórum global de pesquisa e inovação para mobilizar ações internacionais de resposta à Covid-19. Este teve a participação de cientistas especialistas do tema, representantes de institutos de pesquisa, de órgãos públicos de saúde, ministros da saúde e financiadores de pesquisa que se comprometeram a colaborar nas pesquisas e no combate ao novo coronavírus, incluindo a busca por insumos de prevenção e tratamento (WHO, 2021b).

No dia 11 de março, a organização caracterizou a Covid-19 como uma pandemia, conclamando a comunidade internacional a cooperar para o combate ao vírus. Esta foi acompanhada por uma série de medidas concretas, como o estudo global denominado ensaio clínico Solidariedade, uma conjugação de esforços mundiais, de muitos países, coordenados pela OMS para dar resposta rápida sobre a eficácia de medicamentos no tratamento da doença. Além de estudos, a organização também lançou ou atualizou planos de contenção da Covid-19, como o plano estratégico que buscava: mobilizar todos os setores para a participação da resposta; controlar casos para prevenir a transmissão comunitária; suprimir a transmissão comunitária através de medidas como distanciamento físico; reduzir a mortalidade através de assistência clínica adequada; e desenvolver vacinas seguras, eficazes e acessíveis (WHO, 2021b).

Preocupada com o intercâmbio de informações, participação de todos os países e coordenação de esforços, a organização construiu ou reforçou espaços e ferramentas digitais, como a Plataforma de Parceiros Covid-19 e a Rede Global de Alerta e Resposta (BUSS, ALCÁZAR e GALVÃO, 2020). Além disso, em abril de 2020, ela lançou a iniciativa Covax Facility, fruto de uma

\footnotetext{
7 Segundo Deisy Ventura e Fernanda Aguilar Perez (2014), é possível dividir as funções da OMS em três categorias mais amplas, a saber: luta contra as grandes patologias e a organização da vigilância epidemiológica, estipulando direitos e obrigações dos Estados, regulamentações de transportes internacionais e medidas para evitar a propagação de enfermidades; elaboração de normas sanitárias internacionais; e intervenções sanitárias. Para lográ-las, a Organização conta com uma estrutura ampla, constituída também por seis escritórios regionais presentes na África, Américas, Ásia, Europa, Mediterrâneo Oriental e Pacífico, que formulam diretrizes para as respectivas regiões e executam as decisões da sede em Genebra.
} 
aliança internacional que entende que a pandemia precisa ser eliminada globalmente e que, para isso, era preciso acelerar a produção e distribuição de tratamentos à Covid-19 .

Nos meses subsequentes, a Organização promoveu reuniões virtuais, como a Assembleia Mundial da Saúde, e aprovou resoluções, como a WHA 73.1 intitulada "Resposta à Covid-19" a fim de endossar pontos fundamentais para o enfrentamento da pandemia e suas repercussões negativas, sobretudo na saúde física e mental, na economia e na sociedade. Na resolução também estabeleceuse que a responsabilidade pela adoção e aplicação de respostas à pandemia específicas para seu contexto nacional e mobilização dos recursos era exclusivamente dos governos nacionais. Portanto, a OMS continuaria atuando somente como autoridade reitora e coordenadora em assuntos de saúde internacional9.

Estas e outras ações realizadas pela OMS podem ser acompanhadas em uma linha do tempo construída pela própria Organização e disponibilizada em seu site oficial ${ }^{10}$, cobrindo o período de dezembro de 2019 até abril de 2021. Nela podemos identificar todas as ações realizadas que se referem à informação, ciência, liderança, recomendação, resposta e recursos ${ }^{11}$.

\begin{abstract}
8 Partindo de uma concepção de que o acesso à vacina deve ocorrer de forma justa, igualitária e independente da condição financeira dos países, a iniciativa de cooperação internacional visa ampliar a distribuição de imunizantes e garantir que nações de baixa renda não sejam negligenciadas. Para auxiliar no acesso universal e proporcional à vacina, convidou países de renda alta e média-alta a criarem um fundo coletivo para comprarem injeções em conjunto a fim de baratear os preços e ampliar o acesso, especialmente para os países de renda baixa (GAVI, 2021). Também em abril, um grupo de associações de saúde pública, academias científicas e autoridades políticas enviou uma carta ao secretário-geral da ONU solicitando que se instalasse na OMS um grupo de trabalho que versasse sobre a equidade em saúde.

9 Ao longo deste período, alguns Estados-membros da Organização, como os Estados Unidos governado por Donald Trump, criticaram a atuação da OMS no combate à pandemia, inclusive acusando-a de estar em conluio com a China. Em carta ao diretor-geral da OMS, de maio de 2020, Trump ameaçou-o dizendo que o congelamento do repasse das contribuições norte-americanas à Organização, iniciado em abril, poderia tornarse permanente. Ele também mencionou que poderia desligar-se da organização caso ela não se comprometesse com "grandes melhorias substantivas". Estas atitudes, que explicitam os conflitos existentes nos espaços que auxiliam a cooperação internacional, tiveram repercussão nacional, sendo que muitos países se mobilizaram para aumentar suas contribuições à organização. Igualmente, a sociedade civil também se mobilizou manifestando seu desacordo e repúdio (BUSS, ALCÁZAR e GALVÃO, 2020).

${ }^{10}$ Para maiores informações sobre a linha do tempo, ver: https://www.who.int/emergencies/diseases/novelcoronavirus-2019/interactive-timeline\#category-Information. Acesso em 09/07/2021.

${ }^{11}$ Informação refere-se ao compartilhamento dos principais dados da pandemia, como sobre: o aparecimento do vírus, variantes, número de contagiados e mortos, região do mundo que figurou/a como epicentro da doença, impactos do Covid-19, resultados de pesquisas, bancos de dados, encontros e conferências realizados ou mesmo das informações prestadas pelos países e vacinas produzidas. Ela também se refere ao canal de comunicação que a Organização procurou estabelecer com os países e as sociedades civis por meio do seu site, podcasts, YouTube, WhatsApp, entre outros canais. A ciência trata estritamente das ações científicas realizadas pela OMS, entidades parceiras e especialistas a respeito: da compreensão do aparecimento, formas de contágio e das novas variantes do vírus; dos estudos realizados para o combate ao coronavírus; das pesquisas para a criação de vacinas e da sua eficácia ante as novas variáveis; e dos desdobramentos da Covid19 nos locais de atendimento à saúde. A liderança reúne os acordos, declarações e participações de Tedros Adhanom, Diretor-Geral da OMS, em encontros, reuniões, conferências, campanhas e demais eventos sobre a crise sanitária e seus desafios, referentes ao compartilhamento de informações, ao impedimento da disseminação da desinformação, ao "financiamento sustentável" da Organização, ao combate coletivo, à solidariedade global e à cooperação mundial, ao acesso equitativo às vacinas e à mitigação dos impactos do Covid-19 nos meios de subsistência, de saúde e de sistemas alimentares. Também reúne as coalizões e iniciativas da OMS com outras entidades parceiras. Finalmente, abarca declarações que revelam os esforços retóricos de algumas lideranças dos Estados e das sociedades civis em determinadas ocasiões, como na Cúpula Extraordinária do Covid-19 do G20, na Assembleia Geral da ONU, na $73^{\text {a }}$ Assembleia Mundial da Saúde, na
\end{abstract}


Embora tenha atingido todos os países do mundo, a pandemia teve momentos e ritmos diferenciados nos variados Estados. Estes foram acompanhados por respostas específicas, de caráter regional e local. No caso da América Latina, as ações mais gerais da OMS foram supervisionadas pela Organização Pan-Americana da Saúde (OPAS), que é escritório regional para as Américas da OMS e agência especializada em saúde do Sistema Interamericano. A OPAS conta com o auxílio de entidades regionais de trabalho, como o Mercosul.

Especificamente sobre o Mercosul, de acordo com Bárbara Carvalho Neves e Gabriela Dorneles Ferreira da Costa (2020), o histórico de questões sanitárias e de saúde no bloco remontam ao início dos anos 2000 quando foram coordenadas pela assinatura da Carta de Compromisso Social de Buenos Aires ${ }^{12}$. Atualmente, o Mercosul conta com dois espaços que têm a saúde como principal

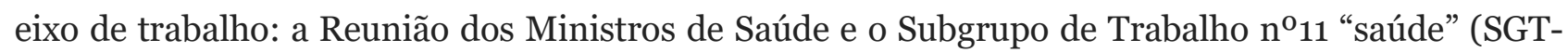
$11)^{13}$.

Diante da disseminação do vírus pelo mundo, em fevereiro de 2020, o Paraguai, então presidente pro tempore do bloco, convocou uma reunião extraordinária com os Ministros da Saúde do Mercosul para o dia 19 do mês corrente, em Assunção. A III Reunião Extraordinária dos Ministros da Saúde do Mercosul contou com a presença de Ginés González Garcia, Julio Mazzoleni Insfrán, Raquel Rosa e Luiz Henrique Mandetta, então Ministros da Saúde do Paraguai, Argentina, Uruguai e Brasil, respectivamente. Na reunião foi discutida a situação da dengue, do sarampo e do novo coronavírus na região do Mercosul, bem como estratégias para o enfrentamento em conjunto destas doenças, especialmente do novo coronavírus (GOVERNO DO BRASIL, 2020).

Após as discussões, os presentes assinaram um projeto de intenções para o compartilhamento de informações e tecnologias denominado "Declaração dos Ministros de Saúde do Mercosul perante a situação epidemiológica de Dengue, Sarampo e Coronavírus (COVID-2019)”.

Cúpula Mundial da Saúde, entre outros. A recomendação apresenta uma série de publicações da OMS, com orientações referentes: ao surto de uma nova doença; alertas epidemiológicos e recomendações acerca de viajantes internacionais, prevenção de infecções e medidas de controle e testes laboratoriais; diretrizes diversas; esclarecimentos sobre tratamentos; considerações sobre quarentena, saúde mental, violência contra a mulher e funcionamento de escolas e outras instituições; manuais sobre gerenciamento de centros de tratamentos de infecções; resumos das políticas para prevenir e mitigar o impacto do Covid-19 em distintos aspectos; orientações para auxiliar os governos nacionais a desenvolver e atualizar seu plano nacional de implantação e vacinação para as vacinas Covid-19; entre outros. A resposta abarca os esforços, as ações e iniciativas concretas da OMS, dos Estados, das entidades parceiras e da sociedade civil no enfrentamento da pandemia, incluindo os resultados do Covax Facility. Nos recursos figuram os financiamentos recebidos, fundos arrecadados, gastos e os programas implementados por meio deles.

${ }^{12}$ A carta estabelecia obrigações para que o acesso integral aos serviços de saúde nos territórios nacionais fosse alcançado. Ainda segundo as autoras, como evolução do caráter social do mecanismo, em 2012, foi estabelecido o Plano Estratégico de Ação Social (PEAS), que estabeleceu em seu Eixo 3 de ações - Universalização da Saúde Pública-, algumas diretrizes, como garantir o acesso à serviços integrados de saúde pública, de qualidade e humanizados e ampliar a capacidade nacional e regional em matéria de investigação e desenvolvimento no campo de saúde.

${ }_{13}$ O SGT-11 tem como principal objetivo harmonizar as políticas estratégicas vinculadas à saúde pública com as prioridades regionais. Também conta com planos e programas de ação para sua implementação conjunta, algo que pode ser notado nos memorandos assinados entre o Mercosul e a OPAS em anos mais recentes, como 2015 e 2019 (OPAS/OMS, 2021). 
Entre as medidas estabelecidas pelos países-membros no documento, figuram o compromisso de: estabelecer ações regionais de vigilância e assistência em saúde; solidarizar-se com os países que estão enfrentando o surto diretamente; instruir as instâncias técnicas de competência no Mercosul "saúde" a estabelecer um mecanismo de coordenação e comunicação periódica para a vigilância e o acompanhamento do Covid-19; e insistir na importância de promover a cooperação horizontal sulsul entre os países da região, bem como incentivar e envolver todos os níveis de governo e demais setores no desenvolvimento de novas tecnologias, capacidades e competências em saúde pública (MERCOSUL, 2020a).

De modo geral, as medidas estabelecidas pelo bloco convergiam com as recomendações que estavam sendo propostas ou que futuramente seriam pela OMS. Contudo, estamos de acordo com Neves e Costa (2020) ao ponderarem que, apesar da reunião extraordinária, não foram adotadas medidas comuns ou práticas para a prevenção ou enfrentamento do surto de Covid-19 nos países do Mercosul. Uma semana após a reunião extraordinária dos Ministros da Saúde do Mercosul, começaram os registros dos primeiros casos de Covid-19 entre os países do bloco.

Devido ao avanço da doença na região, no dia 17 de março de 2020, os presidentes dos países-membros do Mercosul e os mandatários da Bolívia, Chile, Colômbia, Peru e Equador se reuniram virtualmente para acordar questões comerciais e econômicas. Além destes temas, os governantes destacaram a "necessidade de um trabalho conjunto em torno das medidas sanitárias em nível regional” (MERCOSUR, 2021a). Este trabalho seria conformado a partir de preocupações, como compras públicas conjuntas, fomento ao comércio e à economia, pronta recuperação econômica e controle de fronteiras.

No dia seguinte ocorreu uma reunião virtual entre os chefes de Estado e altos representantes do Brasil, Paraguai, Uruguai e Argentina, convocada pelo Paraguai. A partir desta reunião foi emitida a "Declaração dos presidentes do Mercosul sobre coordenação regional para a contenção e mitigação do coronavírus e seu impacto". Logo no início da declaração, eles consideraram "que a pandemia causada pela Covid-19 não respeita fronteiras, requerendo uma coordenação regional eficiente $e$ permanente, sustentada em boas práticas baseadas em evidência científica e em diretrizes emitidas por organizações competentes” (tradução nossa) (MERCOSUR, 2021b).

Além disso, ponderam que os Estados-membros já estavam tomando medidas de prevenção e contenção do vírus e adotando planos estratégicos capazes de oferecer respostas frente aos desafios gerados pela pandemia. Finalmente, consideraram que era necessário gerar espaços de concertação regional multissetoriais que tratassem da problemática sob uma perspectiva "estratégica e solidária”, sendo a cidadania o centro dos seus esforços coletivos.

Em 2 de abril de 2020, o bloco determinou a destinação de 16 milhões de dólares para o combate da Covid-19 nos países-membros. Estes recursos seriam financiados via Fundo para a 
Convergência Estrutural do Mercosul (FOCEM) ${ }^{14}$. Em maio, ocorreram reuniões ordinárias da Comissão de Vigilância da Saúde (COVIGSAL) conjuntamente com a Subcomissão Controle Sanitário de Portos, Aeroportos, Terminais e Pontos de Fronteira Terrestres (SCOCONTS) e da Comissão de Serviços de Atenção à Saúde (COSERATS), ambas subordinadas ao SGT-11. Neste mês, o Mercosul financiou 50 mil kits PCR de diagnóstico de Covid-19 e 400 mil testes sorológicos através do FOCEM (MERCOSUL, 2020b).

Nos dias 9 e 10 de junho, o SGT-11 realizou uma reunião ordinária para tratar das iniciativas referentes à saúde pública em geral. Diferentemente, no dia 18 do mesmo mês, ocorreu a XLVI Reunião Ordinária de Ministros da Saúde. Após a reunião foi publicada a "Declaração de Ministros da Saúde do Mercosul sobre COVID-19”. Novamente, embora seja possível identificar uma convergência com as recomendações da OMS, o documento revela mais as boas intenções e comprometimento com boas práticas do que um avanço concreto na colaboração regional ao combate da pandemia.

Em julho foi realizada, de maneira remota, a $56^{a}$ Cúpula de Presidentes do Mercosul. Após a Cúpula, foram publicados o "Comunicado Conjunto de Presidentes dos Estados Partes do Mercosul e Estados Associados" e o "Comunicado Conjunto dos Presidentes dos Estados Partes do Mercosul". Os documentos diferem dos anteriormente mencionados por considerarem, ainda que de maneira indireta, de forma mais ampla, as distintas dimensões da crise pandêmica, como sanitária, econômica-comercial, ambiental, humanitária (cidadania e trabalho), cultural e social (MERCOSUL, 2020c; MERCOSUL, 2020d).

No âmbito sanitário, destacaram o compartilhamento de informações sobre a situação epidemiológica nos países, das ações de vigilância e assistência em saúde e das medidas sanitárias para a luta contra a pandemia. Também estabeleceram o compromisso de incrementar a cooperação horizontal entre os Estados-membros por meio de acordos que permitam a disponibilidade da vacina, tratamentos e novas tecnologias e articulação de medidas harmonizadas de vigilância epidemiológica e controle sanitário nas fronteiras.

Em outubro de 2020, o Mercosul aprovou novos recursos para o combate da pandemia por meio do FOCEM, beneficiando o Uruguai (MERCOSUL, 2020e). Em dezembro de 2020, os presidentes dos Estados-membros e associados no Mercosul, reuniram-se em videoconferência por ocasião da LVII Cúpula dos Presidentes do Mercosul. Após a reunião, um comunicado conjunto dos presidentes dos Estados partes e Estados associados do Mercosul foi emitido5. Este comunicado é o

\footnotetext{
${ }^{14} \mathrm{O}$ valor contribuiria no projeto Investigação, Educação e Biotecnologias aplicadas à Saúde, criado junto ao Fundo no ano de 2011, devendo ser destinado à pesquisa e ao desenvolvimento em questões referentes ao coronavírus.Inicialmente, um terço deste valor seria dedicado ao fortalecimento da capacidade de diagnóstico do vírus, compra de equipamentos, materiais de proteção e kits para a detecção do vírus. A segunda parte do valor seria destinada à detecção do grau de penetração do vírus na população, de acordo com o cronograma de prioridades de cada país (FOCEM, 2020).

${ }_{15} \mathrm{Na}$ ocasião também foram aprovadas as seguintes declarações: Declaração de Ministros de Saúde do Mercosul e Estados Associados sobre Assistência Alimentar a populações vulneráveis no marco do Covid-19; Declaração dos Ministros de Saúde do Mercosul e Estados Associados sobre o Mecanismo COVAX; Declaração
} 
mais amplo que encontramos a respeito da pandemia e seus distintos desdobramentos, sendo composto por quarenta disposições que versam diretamente sobre as variadas dimensões dos impactos da pandemia nas sociedades.

Em 2021 a pandemia persiste, mas foi agravada em algumas regiões e países, como é o caso da América Latina que, paulatinamente, tornou-se o epicentro da doença, conforme podemos ver na ilustração da Figura 1 com os dados de mortes confirmadas por Covid-19 cumulativamente por milhão de habitantes da Our World in Data (2021) de 30 de julho de 2021.

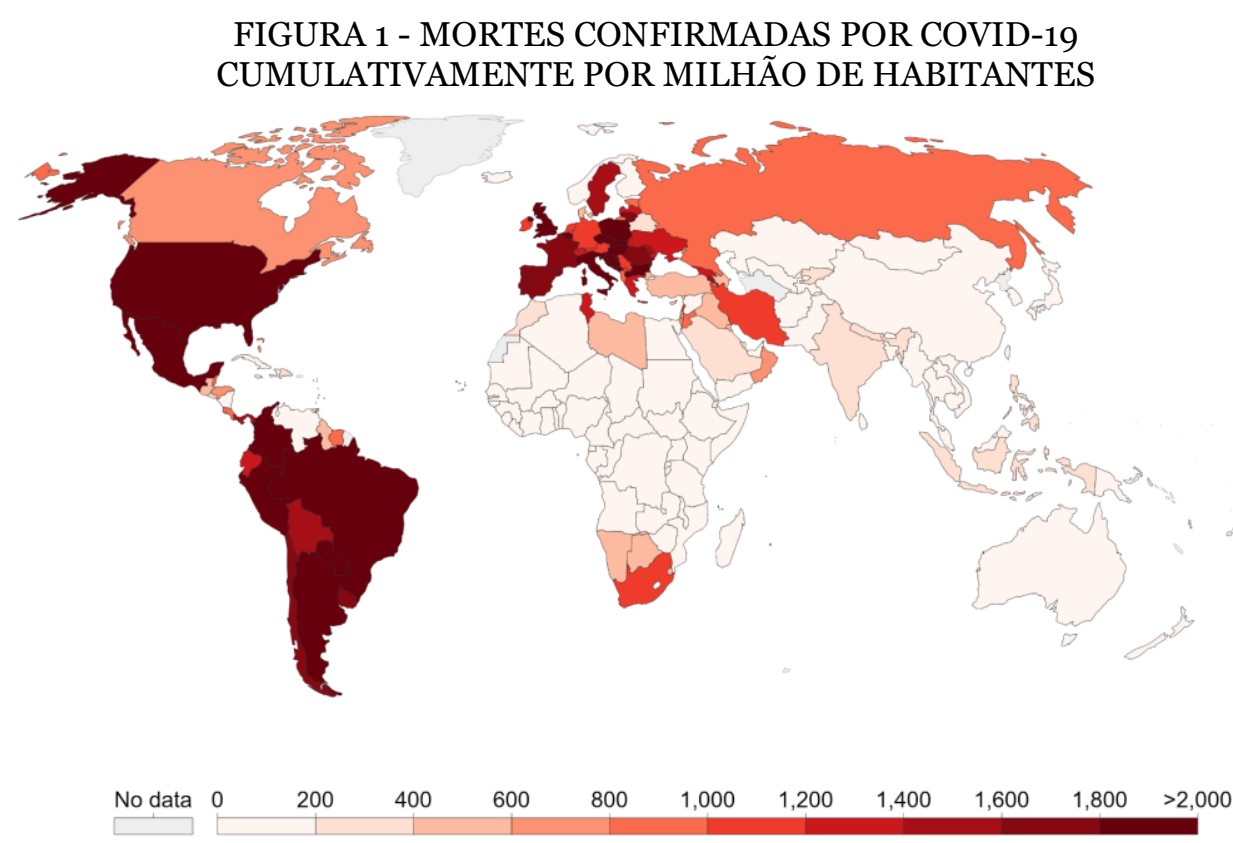

Fonte: Our World in Data (2021).

Neste ano também estão sendo desenvolvidas, testadas e aplicadas diferentes vacinas contra Covid-19. No entanto, há uma desigualdade no acesso e no desenvolvimento às vacinas em algumas regiões como a América do Sul e a África, algo que a OMS e outros atores internacionais têm tentado contornar com a iniciativa Covax Facility. Esta desigualdade gerou uma mobilização dos países que não conseguem ter acesso à vacina na Organização Mundial do Comércio (OMC) solicitando a suspensão temporária das patentes das vacinas.

Especificamente sobre o Mercosul, em abril de 2021, o Parlamento do Mercosul (Parlasul) ${ }^{16}$ debateu uma proposta argentina de o bloco manifestar-se favoravelmente à suspensão temporária das patentes. Contudo, até junho de 2021, encontramos uma declaração favorável ao acesso universal de uma vacina contra a Covid-19, que foi aprovada por parte do Parlasul, mas não foi

dos Ministros de Saúde do MERCOSUL e Estados associados sobre a importância de garantir a saúde ambiental e do trabalhador no contexto da pandemia pela Covid-19 (GUB.UY, 2021).

${ }^{16} \mathrm{O}$ Parlasul é um espaço importante para observar as discussões acerca de outras dimensões que foram impactadas pelo Covid-19 e a participação de outros atores para o combate à pandemia, sobretudo da sociedade civil. As temáticas e as atividades realizadas, ao longo de 2020 e 2021, revelam uma preocupação com as questões econômicas (recuperação), educacionais, de gênero, sanitária (vacinas), infraestrutura, entre outros. 
possível identificar se o tema avançou (RÁDIO SENADO, 2021; PARLAMENTO DO MERCOSUL, 2021).

A despeito das declarações e das disposições propositivas para o combate ao novo coronavírus promovidas pela OMS e pelo Mercosul que reunimos nesta primeira parte do artigo, ao longo da pandemia assistimos a uma série de tensões e desencontros entre os países-membros do bloco. Estas serão abordadas mais especificamente no próximo tópico.

\section{O COMBATE À PANDEMIA PElOS ESTAdos-MEMbros Do MERCOSUL E OS IMPACTOS INTERNOS}

Desde a declaração da pandemia do novo coronavírus feita pela OMS, os presidentes dos quatro países-membros do Mercosul manifestaram preocupação com a Covid-19. Contudo, desde março de 2020 até junho de 2021, eles têm tomado posicionamentos e medidas distintas para conter o avanço da doença em seus países. De modo geral, no primeiro semestre de 2020, as primeiras declarações de Jair Bolsonaro, Alberto Fernández, Mario Abdo Benítez e Luis Lacalle Pou, presidentes do Brasil, Argentina, Paraguai e Uruguai, respectivamente, convergiram por considerarem uma situação de emergência e anunciarem as medidas que seriam adotadas domesticamente para o combate à pandemia. Entre as medidas comuns adotadas inicialmente, figuram: fechamento e controle das fronteiras, quarentenas e medidas de isolamento social e auxílios econômicos. Além destas, também houve a suspensão de eventos públicos e o uso obrigatório de máscaras em espaços públicos.

Apesar destas medidas comuns, que inclusive coincidem com o que estava sendo ou seria recomendado pela OMS, quando comparamos os países, notamos que muitas delas foram tomadas em tempos e de maneiras distintas. Em relação ao fechamento de fronteiras, o Paraguai fechou as fronteiras antes mesmo de o vírus chegar, o que permitiu que a pandemia fosse mais controlada em um primeiro momento. Brasil, Argentina e Uruguai também fecharam suas fronteiras aéreas e terrestres, mas após a chegada do vírus. A despeito do fechamento inicial, os países abriram e voltaram a fechar em tempos distintos.

O Brasil, em meados de 2020, fechou fronteiras aéreas e terrestres. Mais recentemente, em meados de 2021, o país manteve apenas fronteiras terrestres fechadas e reabriu as aéreas, denotando uma seletividade da circulação de pessoas dentro do país, o que gerou uma série de protestos da sociedade civil (VEDOVATO e ASSANO, 2021). A Argentina também fechou no início de 2020, reabriu em outubro de 2020 e restringiu a entrada de pessoas no final do ano. O Uruguai havia fechado no início da pandemia, abriu e voltou a fechar no final de 2020 devido ao crescimento exponencial da doença. Neste contexto de fechamento das fronteiras, o país chegou a restringir a entrada ou o retorno dos seus cidadãos ao país no final de 2020 (COLOMBO, 2021), algo que 
também observamos na Argentina (UOL, 2021). No início de 2021, devido às novas variantes do coronavírus e ao crescimento dos casos no Brasil, Argentina, Uruguai e Paraguai ${ }^{17}$ decidiram restringir a circulação ou fechar as fronteiras ${ }^{18}$ com o país (CARMO, 2021).

Com relação à quarentena e às medidas de isolamento social, no Brasil, o governo iniciou a pandemia apenas adotando recomendações de distanciamento social, deixando que os estados e os municípios decidissem por medidas mais específicas, como as quarentenas (BBC, 2020b). Deste modo, há uma variação nas práticas adotadas pelos estados e municípios brasileiros. Na Argentina, inicialmente, adotou-se uma rígida quarentena nacional, com o fechamento de atividades não essenciais e com uma restrição da circulação de pessoas que não fossem trabalhadores essenciais (profissionais da saúde, da área de alimentação, da distribuição de combustível, políticos, diplomatas e jornalistas). No Uruguai, não houve uma quarentena obrigatória, pois, segundo Lacalle Pou, isto estaria em desacordo com seus princípios de liberdade (COLOMBO, 2021). No Paraguai, houve um isolamento inicial de praticamente três meses. A partir de maio de 2020, adotou-se o que eles denominaram de "quarentena inteligente", um processo de relaxamento das medidas mais rígidas de isolamento social e reabertura de restaurantes e afins (ACUÑA, 2020).

As medidas inicialmente adotadas também estão associadas à maneira com que os presidentes lidaram com a pandemia e com as recomendações da OMS. Antes mesmo da pandemia, um dos principais entraves à busca de maior cooperação entre Brasil e Argentina, principais atores e condutores do processo de integração, foi a rivalidade ideológica e política que existe desde que o presidente argentino Alberto Fernández assumiu o poder em 2019. Esta falta de afinidade gerou um descompasso em um momento de emergência que clamava pela sua superação. Alegando a prevenção contra os efeitos da pandemia e proteção às empresas, empregos e a situação das famílias mais humildes, a desconformidade entre os governos levou à retirada da Argentina da negociação do acordo de livre-comércio entre o Mercosul e a União Europeia deixando-o em compasso de espera (ARREDONDO, 2020; TÁVORA, 2020).

Quando observamos as declarações e as ações dos presidentes, desde março de 2020 até junho de 2021, percebemos um contraste entre o Brasil e os demais países-membros do bloco. No Brasil, paulatinamente, Jair Bolsonaro foi adotando um discurso de crítica à ciência e elogio à

\footnotetext{
17 Para acompanhar as medidas tomadas pelos governos brasileiro, argentino, uruguaio e paraguaio, respectivamente, $\quad$ ver: $\quad$ https://www.gov.br/cgu/pt-br/coronavirus/governo-federal; https://www.argentina.gob.ar/coronavirus/medidas-gobierno; https://www.gub.uy/presidencia/politicas-ygestion/medidas-del-gobierno-para-atender-emergencia-sanitaria-coronavirus-covid-19; https://www.mspbs.gov.py/noticias.php.

${ }^{18}$ A restrição ou fechamento de fronteiras gerou impactos negativos no turismo e nos movimentos migratórios, mas também comprometeu o fluxo transnacional diário de bens, serviços e pessoas, especialmente na Tríplice Fronteira entre Argentina, Brasil e Paraguai. Pela ponte internacional entre Foz do Iguaçu (Brasil) e Ciudad del Este (Paraguai) transitam diariamente 40 mil carros de pessoas indo ao trabalho e à escola, constituindo a travessia de fronteira mais movimentada do Brasil. Ciudad del Este é a terceira maior zona de livre-comércio do mundo, sendo 95\% do seu comércio gerado por brasileiros. Por isto, houve uma exigência de associações comerciais pela liberalização e abertura controlada das fronteiras para o tráfego internacional por medo de que o "vírus brasileiro" rapidamente entrasse pelas fronteiras do Paraguai, Argentina e Uruguai (ROSS, 2020).
} 
"ciência alternativa". Esta possibilitou estímulos à adoção de soluções simples para o combate à Covid-19, como a promoção do tratamento precoce e do uso de alguns medicamentos com eficácia não comprovada cientificamente para o combate à Covid-19 (CASARÕES e MAGALHÃES, 2020). A insistência no tratamento precoce e no uso destes medicamentos contraria as recomendações e os estudos produzidos pela OMS acerca dos medicamentos que não demonstraram eficácia no combate à Covid-19 (OMS, 2021).

Já Fernández, Benítez e Lacalle Pou adotaram discursos mais próximos à ciência, valorizando a importância do conhecimento científico e da colaboração dos cientistas para o combate à pandemia. Além disso, enquanto os presidentes da Argentina, Paraguai e Uruguai reconheciam o trabalho da OMS e seguiam as recomendações de seus Ministros da Saúde e assessores médicos e sanitaristas, o Brasil teve uma postura mais crítica à Organização e a algumas das suas recomendações, especialmente as que trataram da hidroxicloroquina. O presidente Bolsonaro chegou a declarar, em junho de 2020, que o Brasil poderia sair da OMS por ela atuar segundo um "viés ideológico” e que “(...) não precisamos de ninguém de lá de fora para dar palpite na nossa saúde aqui dentro" (AGÊNCIA BRASIL, 2020). Uma expressão deste contraste é que o Brasil, em plena pandemia, está no quarto Ministro da Saúde enquanto os demais países, com exceção do Paraguai, seguiram com o mesmo.

As distintas percepções contribuem para o aumento dos desafios da cooperação internacional no combate à pandemia entre os países-membros do Mercosul. Em dezembro de 2020, em uma reunião com os Ministros da Saúde dos países-membros do Mercosul, o então Ministro da Saúde do Brasil, Eduardo Pazzuelo afirmou que a mudança de protocolo que passou a orientar o tratamento da Covid-19 "fez e faz toda a diferença” na evolução da doença no Brasil. Em seguida, endossou a importância de os países adotarem medidas alinhadas (MACHADO, 2020). Contudo, há uma nítida diferença na abordagem do tratamento entre o Brasil e os demais países.

Com relação aos auxílios econômicos, vale lembrar que o impacto econômico e social da COVID-19 na América Latina foi maior do que em outras regiões emergentes e desenvolvidas, afetando, assimetricamente, os grupos mais vulneráveis e elevando índices do trabalho informal. Estes índices de informalidade na região, que chegaram próximos de 60\% - além dos trabalhadores sem qualquer proteção ou assistência social -, tornaram a situação dramática do ponto de vista social (OECD, 2020).

A região entrou na pandemia do coronavírus com a maioria dos seus países apresentando um baixo potencial de crescimento e um aumento do descontentamento social. Entre os anos de 2014 e 2019, a região apresentou o período mais fraco de crescimento desde os anos de 1950 (OECD, 2020). A economia entre os países do Mercosul, que já não vinha de bons resultados, terminou 2019 com uma taxa de crescimento média nula, agravando a situação em 2020, conforme a Tabela 1 referente à taxa de crescimento do PIB total dos países do Mercosul com os dados da CEPAL (2021a). 


\section{TABELA 1 - TAXA DE CRESCIMENTO ANUAL DO PIB TOTAL A PREÇOS CONSTANTES DE MERCADO} (EM PERCENTUAL)

\begin{tabular}{ccc}
\hline País/Bloco & Ano 2019 & Ano 2020 \\
\hline Argentina & $-2,1$ & $-10,5$ \\
Brasil & 1,4 & $-5,3$ \\
Paraguai & 0 & $-1,6$ \\
Uruguai & 0,2 & $-4,5$ \\
Mercosul & $-0,1$ & $-5,5$ \\
\hline
\end{tabular}

Fonte: Tabela elaborada pelos autores através de dados obtidos em CEPAL (2021a).

A projeção de crescimento do Produto Interno Bruto (PIB) da CEPAL até aumentou, elevando as projeções para os anos de 2021 e 2022 para a região, com valores de 5,2\% e 2,9\%, respectivamente. Para o Brasil, a projeção é de uma alta de 4,5\% para 2021 e de 2,3\% para 2022, ambos resultados abaixo da média da América Latina. Os problemas estruturais que limitavam o crescimento antes da pandemia se agravaram trazendo repercussões negativas na recuperação da atividade econômica, além da dificuldade na retomada do crescimento em 2021 (CEPAL, 2021b). Ainda referente às questões econômicas, mas para além dos dados do PIB, os Investimentos Externos Diretos (IED) feitos na América Latina caíram mais que a média global estimada: no Brasil, uma queda de 45\%, e na Argentina de 35\%, de 2019 para 2020 (OECD, 2020). Do ponto de vista social, em 30 de junho de 2021 a região já acumulava mais de 1 milhão de óbitos por COVID-19 (mais de 32\% do total mundial), dos quais mais de 649 mil só dos países do Mercosul, sendo que a América Latina representa apenas pouco mais de 8\% da população mundial (e o Mercosul ainda menos).

Diante deste cenário, ao longo de 2020 e 2021, os governos adotaram auxílios distintos. Na Argentina estabeleceu-se um auxílio para os trabalhadores e setores mais vulneráveis (“Ingreso Familiar de Emergencia”), uma política de preços máximos de alimentos e o congelamento das tarifas de gás, eletricidade e transporte até o final de 2020. O governo também decretou a proibição das demissões no período de quarentena e o desalojamento de inquilinos que não tivessem como pagar seus aluguéis (COLOMBO, 2021). No Brasil, adotou-se alguns programas para pequenas e médias empresas e um auxílio emergencial mensal de $\mathrm{R} \$ 600,00$ para desempregados e trabalhadores informais, entre abril e junho de 2020. Em julho, o auxílio foi prorrogado por mais dois meses. Em setembro, o governo anunciou uma nova extensão, mas com valor menor. Atualmente, o auxílio segue vigente com um valor menor do que os anteriores (PRATA, 2020; GOVERNO DO BRASIL, 2021).

No Uruguai, adotou-se subsídios de três meses para empresas que contratassem durante a crise, subsídio para trabalhadores mais velhos permanecerem em casa, assistência em dinheiro e alimentos para grupos mais vulneráveis e redução de salário dos funcionários mais bem pagos do serviço público, incluindo o presidente e ministros com a destinação dos recursos para um fundo voltado a ações em resposta à pandemia (COLOMBO, 2021). No Paraguai, ofereceu-se apoio e 
assistência aos trabalhadores mais vulneráveis, alcançando cerca de 60\% destes com subsídios temporários e necessários para o momento.

No que tange aos índices sociais, as transferências emergenciais para os setores de maior vulnerabilidade social apenas atenuaram o aumento da pobreza na América Latina como um todo: a taxa de extrema pobreza atingiu no ano passado 12,5\% - subindo de 70 milhões de pessoas em 2019 para 78 milhões em 2020 - e a de pobreza 33,7\% da população - subindo de 189 milhões em 2019 para 209 milhões em 2020 (CEPAL, 2021b).

As distintas ações adotadas pelos presidentes dos países-membros do Mercosul também contribuíram para a grande diferença do número de contagiados e mortos pela Covid-19, sendo que Argentina, Uruguai e Paraguai eram identificados como países que conseguiram controlar a pandemia. Contudo, no segundo semestre de 2020, a situação começou a mudar. Na Argentina, as medidas que antes eram identificadas de forma positiva por parte da população passaram a ser notadas como negativas, por razões variadas, como pelo comprometimento da dinâmica da economia entre as províncias e pelo cansaço com a quarentena. Estas percepções geraram uma série de protestos contra o governo que misturavam reclamações. Assim, de acordo com Sylvia Colombo (2021), na Argentina, a flexibilização iniciada em agosto de 2020 começou quando a curva de contágios estava em ascensão. Esta flexibilização somada às de setembro e outubro mais o período de festas de fim de ano causaram um novo repique de casos.

No Uruguai, houve uma dificuldade em manter o vírus longe das fronteiras. No Paraguai, a corrupção, a falta de insumos e de medicamentos e o atraso na chegada das vacinas também comprometeram a situação sanitária (CUETO, 2021). Especialmente a partir do segundo semestre de 2020 e início de 2021, têm ocorrido uma série de manifestações contrárias à gestão da pandemia pelos governos, o que podemos observar na Argentina, Brasil e Paraguai (GONZÁLEZ, 2020; JIMÉNEZ, 2021; CARNERI, 2021). Também há registros de manifestações contrárias à vacina e ao isolamento social no Brasil e na Argentina.

Apesar das variadas manifestações nos encontros do Mercosul a respeito da importância de medidas coordenadas para combater a pandemia, em diversos momentos, os países-membros agiram unilateralmente, alguns nem seguindo as orientações da OMS. No momento em que escrevemos este artigo, em meados de julho de 2021, a situação está complicada mesmo entre os países-membros do bloco que adotaram medidas mais combativas contra a Covid-19. O Uruguai, que se mostrava como exemplo mundial de contenção da Covid-19 até final de 2020, passou a sofrer com a entrada da "variante brasileira" em 2021. O Paraguai também era um caso de sucesso, mas, nas últimas amostragens de julho de 2021, ultrapassou os Estados Unidos em número de mortes por milhão de habitantes e é o país em situação mais vulnerável dada a sua dependência econômica com o Brasil (PAIM, 2020). 
A falta de coordenação e ação conjunta pode ser notada na desigual aquisição, distribuição e vacinação, como podemos analisar através da Figura 2 com dados de 30 de julho de 2021 da Our World in Data (CEPAL, 2021b; OUR WORLD IN DATA, 2021).

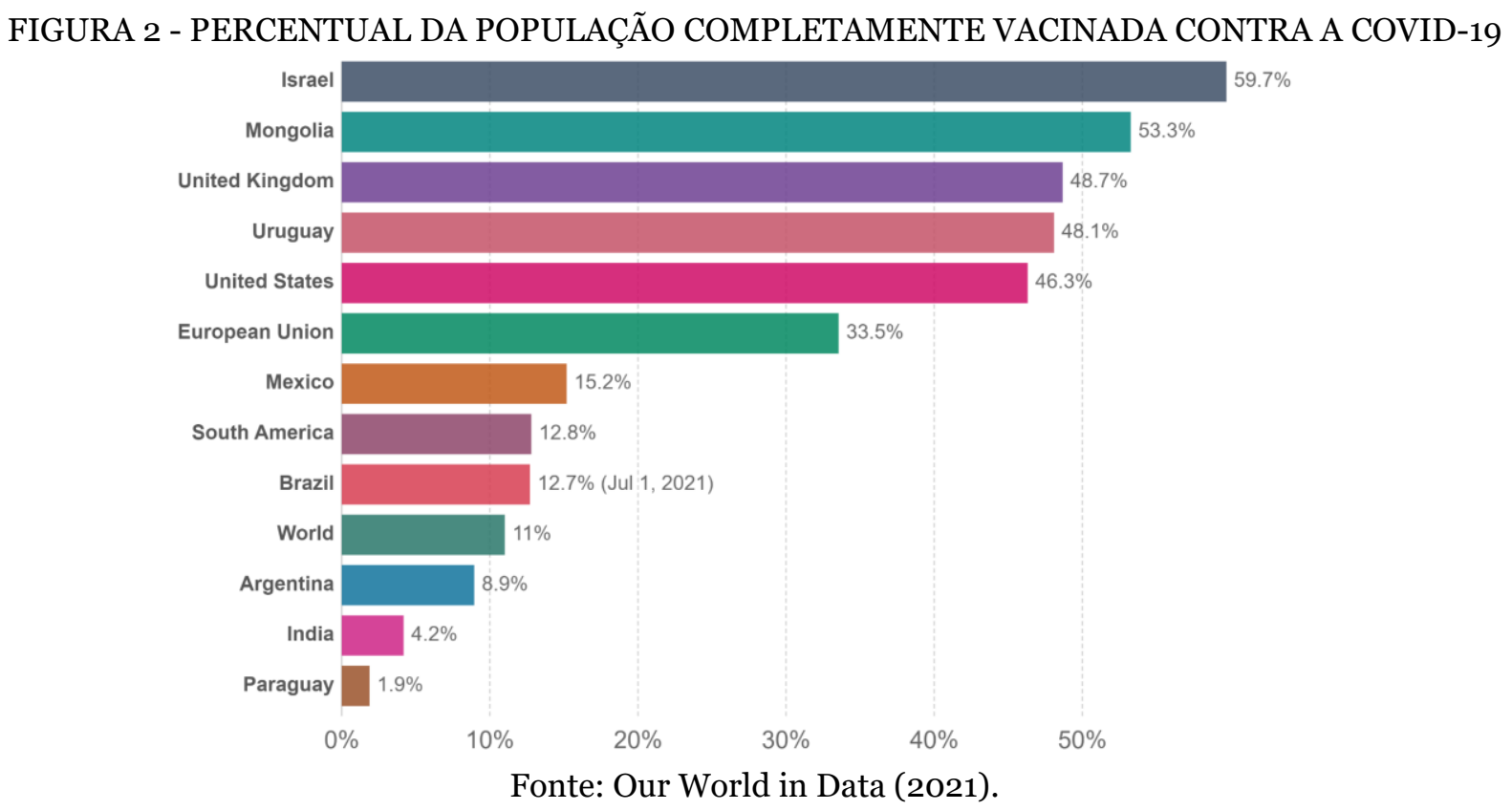

Quanto ao percentual da população total com esquema de vacinação completo dos integrantes do bloco, temos: o Uruguai com 48,1\%, o Brasil com 12,7\%, a Argentina com 8,9\% e o Paraguai com 1,9\%. Enquanto isso, temos países como a Mongólia com 53,3\%, o Reino Unido com $48,7 \%$, os Estados Unidos com 46,3\% e a União Europeia que chegou a 33,5\% da população com esquema de vacinação completo.

\section{CONSIDERAÇÕES FINAIS}

Em momentos marcados por crises, como a sanitária que vivemos, a promoção de medidas coordenadas que possibilitem a cooperação entre os diversos atores, níveis e dimensões do cenário internacional em prol de um "bem comum", como a saúde, têm se mostrado fundamentais. No caso analisado, vimos que a OMS, ao longo de 2020 e 2021, empreendeu uma série de ações a fim de conscientizar e mobilizar organismos internacionais, Estados, blocos regionais e a sociedade civil no combate a um inimigo comum: o novo coronavírus.

Debruçamo-nos sobre a realidade da América do Sul, mais especificamente do Mercosul, para compreendermos se as recomendações da OMS foram seguidas pelo Mercosul, como bloco, e pelos países-membros, domesticamente. Em relação ao Mercosul, as diferenças políticas recentes entre os Estados-membros, oriundas da última eleição presidencial na Argentina, nomeadamente 
entre Jair Bolsonaro e Alberto Fernández, impedem um melhor relacionamento que, ao longo dos últimos 30 anos, era amigável e cordial independente das orientações da política externa. O interesse do bloco se mantém de acordo com o interesse que cada governo coloca neste.

Durante a pandemia, o Mercosul promoveu uma série de encontros com diversas autoridades dos países-membros para tratar sobre a questão, que em boa medida estavam de acordo com as recomendações da OMS. Contudo, na prática, com exceção do controle das fronteiras e dos fundos do FOCEM, ele foi mais um espaço de diálogo e de declaração de boas intenções e do desejo de colaboração comum entre os Estados-membros, especialmente para que estivessem cientes da situação do combate ao vírus nos demais países.

De maneira geral, embora o momento pedisse por mais união e cooperação, o que vimos foi a falta de coordenação de uma política conjunta e eficiente no combate ao coronavírus, conforme recomendado pela OMS. No que tange às políticas públicas aplicadas em cada governo, conforme demonstramos, entre março de 2020 e junho de 2021, na maioria dos casos foram aplicadas unilateralmente pelos Estados-parte e as principais medidas foram tomadas de formas e em tempos distintos. Estas diversidades de ações revelam as variadas percepções dos governantes acerca da pandemia e do seu combate. Elas também geraram efeitos sanitários, econômicos e políticos distintos. No âmbito sanitário, em um primeiro momento, Paraguai, Argentina e Uruguai foram identificados como países que combatiam a pandemia de forma eficaz, diferentemente do Brasil.

A diversidade de ações também indica que a preocupação central dos países era proteger a sua população. Contudo, além de o vírus ultrapassar fronteiras, há desafios comuns que os países estão enfrentando nos âmbitos sanitários, econômicos e sociais, que poderiam ser melhor enfrentados adotando uma maior colaboração. Algumas medidas, como os auxílios econômicos, apenas atenuaram uma situação econômica na região que ficaria em condições ainda piores e, apesar das melhoras nas projeções da CEPAL para a região em 2021 e 2022, o crescimento que teremos para estes anos, por ora, não será suficiente para superar os efeitos nefastos que a pandemia causou e a falta de ações conjuntas corroborou.

Conforme ponderou o cientista político Andrés Malamud ao tratar sobre a pandemia na América do Sul, "um país pode se sair bem sozinho se for uma ilha, como a Nova Zelândia. Na América do Sul, não há isolamento possível e nem cooperação suficiente” (CNN Brasil, 2021). Assim, o diálogo, a cooperação e a coordenação regional efetiva entre os países do bloco poderiam contribuir para um maior combate ao vírus, que envolvesse desde o intercâmbio de experiências e medidas positivas adotadas até o maior acesso aos insumos ou as vacinas contra a Covid-19.

*Artigo recebido em 12 de julho de 2021, aprovado em 04 de outubro de 2021. 


\section{REFERÊNCIAS}

ACUÑA, Jazmín. Quarentena radical. Disponível em: https://piaui.folha.uol.com.br/materia/quarentena-radical/. Acesso em 11/07/2021.

AGÊNCIA BRASIL. Bolsonaro diz que Brasil pode sair da OMS. Disponível em: https://agenciabrasil.ebc.com.br/politica/noticia/2020-06/bolsonaro-diz-que-brasil-pode-sairda-oms. Acesso em 12/07/2021.

ALCAZAR, Santiago; BUSS, Paulo M.; GALVÃO, Luiz Augusto. Pandemia pela Covid-19 e multilateralismo: reflexões a meio do caminho. Estudos Avançados, São Paulo, v. 34, n. 99, p. 4564, Aug. 2020.

ARREDONDO, Ricardo. Mercosur: A New Victim of the Coronavirus? Disponível em: http://opiniojuris.org/2020/05/02/mercosur-a-new-victim-of-the-coronavirus/. Acesso em: 03/07/2021.

BBC. 'É a principal ameaça': situação de pandemia no Brasil gera temor em vizinhos na América do Sul. 2020a. Disponível em: https://www.bbc.com/portuguese/internacional52594649. Acesso em 09/07/2021.

BBC. Coronavírus: o mapa interativo que mostra as medidas e tipos de isolamento adotados na América Latina. 2020b. Disponível em: https://www.bbc.com/portuguese/internacional-52248493. Acesso em 11/o7/2021.

CARMO, Maria. Covid-19: piora da pandemia no Brasil leva países vizinhos a reforçarem medidas nas fronteiras. Disponível em: https://www.bbc.com/portuguese/internacional56360055. Acesso em 11/07/2021.

CARNERI, Santi. Protesto contra a gestão da pandemia termina em violência no Paraguai. Disponível em: https://tinyurl.com/carneri2021. Acesso em 12/07/2021.

CASARÕES, Guilherme; MAGALHÃES, David. "The hydroxychloroquine alliance: how far-right leaders and alt-science preachers came together to promote a miracle drug", Brazilian Journal of Public Administration, Rio de Janeiro, 55(1), p. 197-214, 2021.

CEPAL - Comisión Económica para América Latina y el Caribe. Informe especial no $\mathbf{1}_{\mathbf{1}}$ Covid-19 - América Latina y el Caribe ante la pandemia del COVID-19 Efectos económicos y sociales. 2020. Disponível em: https://tinyurl.com/cepal2020inf1. Acesso em 09/07/2021.

CEPAL - Comisión Económica para América Latina y el Caribe. Anuario Estadístico de América Latina y el Caribe 2020. 2021a. Disponível em: https://tinyurl.com/anuario2020cepal. Acesso em 03/07/2021.

CEPAL - Comisión Económica para América Latina y el Caribe. O crescimento da América Latina e do Caribe em 2021 não conseguirá reverter os efeitos adversos da pandemia. 2021b. Disponível em: https://tinyurl.com/cepalcresclatam2021. Acesso em 10/07/2021.

CNN Brasil. América do Sul vê explosão de casos de Covid e se torna região mais preocupante. 2021. Disponível em: https://www.cnnbrasil.com.br/internacional/2021/o4/15/america-do-sul-ve-explosao-de-casosde-covid-e-se-torna-regiao-mais-preocupante. Acesso em 10/07/2021.

COLOMBO, Sylvia. O ano da cólera: protestos, tensão e pandemia em 5 países da América Latina. Rio de Janeiro: Rocco, 2021. 
CUETO, José Carlos. Coronavirus en Paraguay: 3 claves que explican cómo este país pasó de controlar la pandemia a vivir una doble crisis política y sanitaria. Disponível em: https://www.bbc.com/mundo/noticias-america-latina-56321386. Acesso em 12/o7/2021.

FOCEM - Fundo para a Convergência Estrutural do Mercosul. O Mercosul aprova mais recursos para Projeto FOCEM sobre Biotecnologias aplicadas à saúde, destinados à luta contra o Covid-19. 2020. Disponível em: https://tinyurl.com/verbafocem2020. Acesso em: 03/07/2021.

FONSECA, Leila Oliveira da. Os desafios da cooperação internacional em tempos de pandemia. Revista Relações Exteriores. Disponível em: https://relacoesexteriores.com.br/cooperacaointernacional-pandemia/. Acesso em 11/07/2021.

GAVI. Gavi the vaccine alliance. Disponível em: https://www.gavi.org/covax-facility. Acesso em 11/07/2021.

GLOBO. Presidente da Argentina diz que Brasil é um risco para a região. Disponível em: https://g1.globo.com/bemestar/coronavirus/noticia/2020/05/07/presidente-da-argentina-dizque-brasil-e-um-risco-para-a-regiao.ghtml. Acesso em 9/07/2021.

GONZÁLEZ, Enric. Dezenas de milhares de argentinos se manifestam contra o Governo de Alberto Fernández. 2020. Disponível em: https://tinyurl.com/gonzalez2020elpais. Acesso em 12/07/2021.

GOVERNO DO BRASIL. Governo Federal prorroga por três meses o pagamento do Auxílio Emergencial 2021 à população de baixa renda afetada pela pandemia. 2021. Disponível em: https://tinyurl.com/bra-aux-emerg-2021. Acesso em 11/07/2021.

GOVERNO DO BRASIL. Brasil apresenta expertise na vigilância de doenças transmissíveis a países do Mercosul. 2020. Disponível em: https://tinyurl.com/bra-expertvig2020. Acesso em 03/07/2021.

GUB.UY. XLVII Reunión Ordinaria de Ministros de Salud del MERCOSUR. Disponível em: https://tinyurl.com/gub-uy-2020. Acesso em 03/07/2021.

JIMÉNEZ, Carla. Ruas se movem contra Bolsonaro com revolta reforçada por marca de meio milhão de mortos para a covid-19. Disponível em: https://brasil.elpais.com/brasil/202106-20/ruas-se-movem-contra-bolsonaro-com-revolta-reforcada-por-marca-de-meio-milhao-demortos-para-a-covid-19.html. Acesso em 12/07/2021.

KEOHANE, Robert; NYE, Joseph. Power and interdependence : world politics in transition. Glenview, IL: Scott Foresman, 1989.

MACHADO, Renato. Pazuello diz a ministros da Saúde do Mercosul que tratamento precoce 'fez $e$ faz a diferença' para Covid. Disponível em: https://www1.folha.uol.com.br/equilibrioesaude/2020/12/a-ministros-da-saude-do-mercosulpazuello-diz-que-tratamento-precoce-fez-e-faz-a-diferenca-para-covid.shtml. Acesso em 11/07/2021.

MERCOSUL. Declaração dos Ministros da Saúde do Mercosul perante a situação epidemiológica da dengue, do sarampo e do coronavirus (COVID-2019) no Mercosul. 2020a. Disponível em: https://tinyurl.com/dec-min-mercosul-2020. Acesso em 02/07/2021.

MERCOSUL. Mercosur financia 50.0oo kits PCR de diagnóstico de COVID-19 y 400.00o de serodiagnóstico. 2020b. Disponível em: https://www.mercosur.int/mercosur-financia-50ooo-kits-pcr-de-diagnostico-de-covid-19-y-400-00o-de-serodiagnostico/. Acesso em 03/07/2021. 
MERCOSUL. Comunicado conjunto dos presidentes dos Estados partes do Mercosul. 2020c. Disponível em: https://tinyurl.com/Mercosul-com-estados-pt-2020. Acesso em 03/07/2021.

MERCosul. Comunicado Conjunto de Presidentes dos Estados Partes e Estados Associados do Mercosul. 2020d. Disponível em: https://tinyurl.com/Com-Merc-parte-e-assoc2020. Acesso em 03/07/2021.

MERCOSUL. MERCOSUR aprueba nuevos recursos para el combate contra la pandemia. 2020e. Disponível em: https://tinyurl.com/mercosul-rec-pand. Acesso em 03/07/2021.

MERCOSUR. Os presidentes da região acordam medidas para combater o Covid-19. 2020a. Disponível em: https://tinyurl.com/mercosulcombatecovid. Acesso em 3/o7/2021.

MERCOSUR. Declaracion de los presidentes del Mercosur covid-19. 2020b. Disponível em: https://tinyurl.com/dec-pres-mercosul-covid. Acesso em 03/07/2021.

NEVES, Bárbara Carvalho; COSTA, Gabriela Dorneles Ferreira da. E o Mercosul? Os impasses regionais diante da pandemia de COVID-19. Cadernos de Regionalismo ODR, São Paulo, v. 4, p. 42-51, 2020.

OECD - Organization for Economic Co-operation and Development. COVID-19 in Latin America and the Caribbean: Regional socio-economic implications and policy priorities. 2020. Disponível em: https://tinyurl.com/oecd-latam-imp-covid-2020. Acesso em: 09/07/2021.

OUR WORLD IN DATA. Statistics and Research Coronavirus (COVID-19). Disponível em: https://ourworldindata.org/covid-vaccinations\#what-share-of-the-population-has-been-fullyvaccinated-against-covid-19. Acesso em 09/07/2021.

PAIM, Camila. Distinção de medidas de combate ao coronavírus afeta relações internas e externas do Mercosul, aponta especialista. 2020. Disponível em: https://tinyurl.com/paim2020. Acesso em: 03/07/2021.

PARLAMENTO DO MERCOSUL. PARLASUL apoia o acesso às vacinas contra COVID-19 como um "direito da humanidade". 2021. Disponível em: https://tinyurl.com/parlasul-vaccovid-2021. Acesso em 03/07/2021.

PRATA, Pedro. Argentina, Cuba e Venezuela têm auxílio emergencial na pandemia, ao contrário do que afirma Post. Disponível em: https://politica.estadao.com.br/blogs/estadaoverifica/argentina-cuba-e-venezuela-tem-auxilio-emergencial-na-pandemia-ao-contrario-do-queafirma-post/. Acesso em 11/07/2021.

RÁDIO SENADO. Parlasul vai debater a quebra de patente de vacinas contra a covid-19. 2021. Disponível em: https://tinyurl.com/radiosenado2021-patentes-covid. Acesso em 03/07/2021.

ROSS, Greg. Isolation and integration: COVID-19 in the Southern Cone. Disponível em: https://tinyurl.com/ross2020covid-mercosur. Acesso em 03/07/2021.

SATO, Eiiti. Cooperação internacional: uma componente essencial das relações internacionais. RECIIS - R. Eletr. de Com. Inf. Inov. Saúde, v. 4, n. 1, p. 46-57, 2010.

TÁVORA, Fernando Lagares. O brexit da Argentina (em meio à pandemia de Covid-19 causada pelo novo coronavírus - SARS-CoV-2) e o futuro do Mercosul. Brasília: Núcleo de Estudos e Pesquisas/CONLEG/Senado, 2020. 
UOL. Covid-19: Argentina estende restrições para o retorno de cidadãos ao país. Disponível em: https://tinyurl.com/uol2021. Acesso em 10/07/2021.

VEDOVATO, Luís Renato; ASSANO, Camila. Fronteiras e olhos “bem” fechados. Disponível em: https://tinyurl.com/vedovato-assano-2021. Acesso em 11/07/2021.

VENTURA, Deisy; PEREZ, Fernanda Aguilar. "Crise e reforma na Organização Mundial da Saúde". Lua Nova, São Paulo, 92: p. 45-77, 2014.

WHO. WHO Coronavirus (COVID-19). Dashboard. Disponível em: https://covid19.who.int/. Acesso em 09/07/2021a.

WHO. Timeline: WHO's COVID-19 response. Disponível em: https://www.who.int/emergencies/diseases/novel-coronavirus-2019/interactivetimeline\#category-Information. Acesso em 09/07/2021b. 